\title{
The number 747 is named faster after seeing Boeing than after seeing Levi's: Associative priming in the processing of multidigit Arabic numerals
}

\author{
Jose Ramon Alameda \\ University of Huelva, Spain \\ Fernando Cuetos \\ University of Oviedo, Spain \\ Marc Brysbaert \\ Ghent University, Belgium and Royal Holloway, University of London, UK
}

\begin{abstract}
Two experiments are reported in which naming multidigit Arabic numerals was shown to depend on the context in which the numbers were presented. Number naming and number decisions were faster after an associative prime (e.g., 747 preceded by the word Boeing) than after an unrelated prime, both in unmasked and masked priming conditions. On the basis of these findings, we conclude that number naming is not always based on a quantity-based semantically mediated pathway.
\end{abstract}

Number processing is usually associated with the manipulation of symbols and words that refer to quantities. People use numbers to indicate amounts of goods, and they often perform calculations on these quantities. Recent years have witnessed a number of major breakthroughs in our understanding of such quantitative number processing. Among other things, it has been found that numbers are processed in another cortical area than words (Dehaene, Dehaene-Lambertz, \& Cohen, 1998; Thioux, Seron, \& Pesenti, 1999), that number understanding partly depends on an ordered magnitude representation that is also present in infants and animals (Brannon \& Terrace, 1998; Wynn, 1992), and that small numbers are easier to process than large numbers (Brysbaert, 1995; Dehaene, Dupoux, \& Mehler, 1990).

Requests for reprints should be sent to Fernando Cuetos, Facultad de Psicologia, University of Oviedo, Plaza Feijoo s/n, 33003 Oviedo, Spain. Email: fcuetos@correo.uniovi.es

The authors thank Mark Ashcraft, Patrick Lemaire, and four anonymous reviewers for helpful comments on earlier drafts of this article. This research was partially supported by an FWO grant to Marc Brysbaert and by grant MCT-00-BSO-0315 from the Spanish Government to Fernando Cuetos.

(C) 2003 The Experimental Psychology Society 
In general, the above research has been based on small integer numbers (often single digits). For the processing of larger and more multidigit numbers, it is assumed that some kind of decomposition takes place. McCloskey (1992), for instance, argued that all numbers are recoded as powers of ten before being understood and used (e.g., for calculations). Similarly, Dehaene (1992) hypothesized that large numbers are recoded in a visuo-spatial grid of digits, when the task involves multidigit operations or number parity. Brysbaert (1995) assumed that all the integers from 1 to 99 have a separate representation and can be combined to form multidigit numbers (see also Power \& Dal Martello, 1997). Empirical evidence for the decomposition of large numbers comes from findings on syntactic errors and on number comparison. It has been observed that syntactic errors (i.e., confusion of the relations among digits) occur more frequently for numbers with three or more digits than for numbers with two digits (e.g., Delazer \& Girelli, 1997; Noël \& Seron, 1993). In number comparison, it has been shown that the comparison times of two-digit numbers are not influenced by the similarity of the decade digits (Dehaene et al., 1990). Thus, although it is easier to say that 48 is smaller than 51 than to say that 50 is smaller than 51 (because of the distance between the numbers), it is not easier to say that 48 is smaller than 51 than to say that 51 is smaller than 54. In contrast, when four-digit numbers are compared, there is clear evidence for systematic left-right comparison of the digits until a pair of digits is found that differs (Poltrock \& Schwartz, 1984).

However, numbers do not always denote quantities. In many situations, people use numbers as ordinal signs or even as nominal labels that are void of any magnitude information. A typical example of the former is the use of numbers to refer to years. When people talk about 1992, they are in the first place referring to a time period about 10 years ago rather than to the cardinal number of years elapsed since the beginning of the Christian calendar. In addition, the year 1992 is likely to be associated with memory traces in episodic and semantic memory, and these traces form part of a wider sequence of events that happened shortly before and after. Likewise, numbers are sometimes used as labels to refer to a particular entity. Although these numbers usually had some meaning when they were introduced, that meaning is often not related to quantity and has been lost in everyday use. For instance, the seminar room of the Department of Experimental Psychology at Ghent University is known as Room 402. Although this number refers to the fact that the seminar room is the second room on the fourth floor of the building, this is not the first information that comes to mind when one hears there will be a meeting in 402 . Similarly, few people know where the numbers in Boeing 747 and Peugeot 205 come from (and in general, they don't care).

There is some neuropsychological evidence that numbers, frequently used as ordinal or nominal referents, need not be decomposed by the quantitative number processing system before they can be understood. Cohen, Dehaene, and Verstichel(1994) reported a patient with deep dyslexia who could read words (12/24 correct, with 5 semantic errors) but virtually no nonwords ( $1 / 24$ correct, with 7 word substitutions). When shown elementary numerals (i.e., numerals that are realized verbally by a single word, such as ones, tens, teens, 100, 1000), the patient could name them correctly on 34 of the 42 trials. When confronted with multidigit numbers, there was a difference depending on whether the numbers referred to familiar identities (e.g., $1789=$ the year of the French revolution) or not. For the former type of stimulus, the patient scored 24/52, against 10/52 for the latter type. In addition, for the familiar numbers the patient often produced an adequate commentary about the number, 
demonstrating access to the specific meaning of the item (e.g., when shown 1918 , he said "the end of World War I . . 1940").

Delazer and Girelli (1997) reported another case of an aphasic and dyslexic patient, who was particularly impaired in reading Arabic numerals and whose performance on these stimuli did not improve significantly over a revalidation period of 3 years, whereas his performance on alphabetical stimuli (number words, words, and nonwords) did. Interestingly, the patient's performance depended on the semantic context in which the Arabic numeral was presented. The numeral 164 had more chances of being named correctly when it was preceded by the semantically related words "Alfa Romeo" than by the neutral word "Barilla" (an Italian brand of pasta).

To explain their findings, Cohen et al. (1994) postulated the existence of a visual input lexicon for frequently encountered Arabic numerals. This lexicon would not send information to the quantitative number comprehension system but to stored encyclopaedic knowledge (making the patient read the number 19 as "the age of my daughter"). In addition, Cohen et al. hypothesized that the visual input lexicon could have direct connections to a phonological output lexicon, making it possible for humans to read aloud Arabic numerals without understanding them (see also Cuetos \& Miera, 1998; Dehaene \& Cohen, 1997). Delazer and Girelli (1997), on the other hand, put much less emphasis on the possible existence of an asemantic input lexicon for familiar Arabic numerals but stressed the importance of different types of semantic knowledge associated with numbers. They argued that the associative priming observed in their patient did not so much depend on the visual form of the Arabic numeral or on the intactness of the verbal output system, but on the meaning that could be attributed to the number. The same number could or could not be read, depending on the semantic context in which it was presented. The main difference with quantitative number processing was that the context did not refer to the magnitude of the numbers, but consisted of one or two words frequently co-occurring with the numbers in everyday life.

The discussion about the existence of an asemantic visual input lexicon for familiar Arabic numerals is embedded within a wider discussion of whether Arabic numerals, just like pictures, require pivotal semantic mediation to be named, or whether there is a nonsemantic conversion route from Arabic input to verbal output similar to the nonsemantic letter-sound translations observed in word naming. Some authors defend the existence of such a nonsemantic route (e.g., Cipolotti \& Butterworth, 1995; Cohen et al., 1994; Dehaene, 1992), whereas others see little evidence of it (e.g., Brysbaert, Fias, \& Reynvoet, 2000; Fias, 2001; Fias, Reynvoet, \& Brysbaert, 2001; McCloskey, 1992). Fias et al. (2001), for instance, found that when a digit and a word numeral were presented in the same display, participants could name the word numeral equally fast when the digit referred to the same quantity (e.g., five, 5) or to a different quantity (e.g., five, 3). This is in line with the hypothesis that words can be named without semantic mediation, so that word naming is not affected by the Arabic distractor. In contrast, digit naming was faster when the digit and the verbal numeral were congruent than when they were incongruent, suggesting a greater involvement of the semantic system in digit naming than in word naming. This pattern of asymmetric interference between words and digits is an exact replica of the more general finding of asymmetric Stroop-like interference effects in the naming of pictures and words (Glaser, 1992).

However, nearly all evidence for a strong semantic view of Arabic numeral naming has been based on small integers (mostly single digits) and has started from the assumption that the 
semantic system is the so-called number line (i.e., an ordered meaning system based on the magnitude of the numbers). It is clear that such evidence has little to say about the findings of Cohen et al. (1994) and Delazer and Girelli (1997), which seem to present convincing evidence against a simple model of number processing in which all Arabic numerals must first address a magnitude-based number meaning system before they can be named. However, before accepting this conclusion, we first wanted to find out whether we could replicate the effects with healthy participants. A problem with the patients of Cohen et al. and Delazer and Girelli is that they often took quite long to identify the numbers (e.g., they often used a counting strategy). This makes it difficult to generalize the findings to normal number processing. Maybe there is a link between certain familiar numbers and their associated encyclopaedic knowledge, but this link is slow and requires extensive top-down elaboration of the stimulus. Therefore, the evidence would be more convincing if we could show similar effects in normal participants. In two experiments we look at the existence of associative priming in Arabic numeral processing.

\section{EXPERIMENT 1}

We selected 50 stimulus pairs for which there exists a strong association between a word and an Arabic numeral due either to well-known brand names (e.g., Peugeot 106, Peugeot 205, Boeing 747) or to famous historical events (e.g., guerra mundial 1945, invasion arabe 712; $;^{1}$ see Appendix for the complete list). Primes preceded targets by different stimulus-onset asynchronies (SOAs), but all SOAs were shorter than $250 \mathrm{~ms}$, estimated by Neely (1991) as the critical range within which automatic priming occurs. With longer SOAs, it is generally accepted that the priming may be due to strategic guessing on the basis of expectations.

In the first condition, primes were presented for $200 \mathrm{~ms}$ and immediately followed by the target. This is the condition that comes closest to many of the semantic priming conditions in the literature of visual word recognition (Lucas, 2000; Neely, 1991), allowing researchers to compare our findings with this literature. However, because unmasked primes presented for $200 \mathrm{~ms}$ are clearly visible, in the last decade researchers have increasingly turned to the masked priming paradigm in which primes are shown for a shorter period of time and sandwiched between a forward and a backward pattern mask. If primes in this paradigm are presented for a time period shorter than $60 \mathrm{~ms}$, they usually are invisible (Forster, 1998), making it further unlikely that participants could strategically use information disclosed by the prime to speed up the processing of the target. We included two such conditions, one of a prime duration of 84 $\mathrm{ms}+14 \mathrm{~ms}$ postmask, and one of $57 \mathrm{~ms}+14 \mathrm{~ms}$ postmask. The former condition was included because we feared that some of our stimulus primes might be too long to be processed in $57 \mathrm{~ms}$. Perea and Gotor (1997) reported associative priming for a prime exposure duration of $57 \mathrm{~ms}$ but with word primes that had at most six letters.

\footnotetext{
${ }^{1}$ It might be argued that the latter type of stimulus is of more of a semantic nature than is the former type, which simply consists of a word and a number that are frequently perceived and produced together. However, because the number 1945 is more likely to be encountered more in contexts referring to World War II than to anything else, there probably is an associative relationship between World War and 1945 as well. Therefore, we do not make a distinction between each type of stimulus and simply refer to them as associative primes (see Lucas, 2000, for a meta-analysis of the differences between associative and pure semantic priming).
} 


\section{Method}

\section{Participants}

Three groups of 50 students from the University of Huelva participated in this experiment, one group per SOA.

\section{Stimuli}

The stimuli consisted of 50 Arabic numerals that in everyday life were frequently preceded by a fixed expression of one or two words (e.g., brandy 103, Levi's 501, Barcelona 92). Participants saw half of the numerals preceded by their associated words (e.g., Levi's -501 ) and the other half preceded by unrelated words that were obtained by swapping primes and targets (e.g., Boeing -911 , instead of Boeing -747 , or Porsche -911) according to a Latin square design. The correlation between number magnitude and number $\log$ of frequency (Cuetos \& Alameda, 1997) was -.30 $(n=50, p<.05)$, in line with the more general observation that small numbers on the average are more frequent than large numbers (e.g., Brysbaert, 1995).

\section{Procedure}

There were three types of trial (between groups) depending on the SOA condition. In the first, unmasked, 200-ms condition, a trial started with a fixation point appearing in the centre of the screen for $1 \mathrm{~s}$, immediately replaced by the prime word(s) for $200 \mathrm{~ms}$ and followed by the Arabic numeral which was to be named as fast as possible. In the second condition - the masked $84+14$-ms condition-the fixation stimulus consisted of a row of hash marks (\#) presented for $500 \mathrm{~ms}$, immediately followed by the prime word(s) for $84 \mathrm{~ms}$, a postmask of hash marks for $14 \mathrm{~ms}$, and the Arabic target numeral. The numeral again had to be named. Finally, the last condition - the masked $57+14 \mathrm{~ms}$ condition-in all aspects resembled the second condition, except that the prime was presented for $57 \mathrm{~ms}$. In each condition, response time started at the onset of the target numeral. The 50 test trials were preceded by 15 practice trials. Each participant received a different permutation of the stimulus list.

\section{Results}

Across SOA conditions $6 \%$ of the reaction times (RTs) could not be used because the answer was not correct $(1 \%)$, time registration failed $(1.8 \%)$, or the RT deviated more than $2 S D$ from the mean $(3.3 \%)$. Table 1 shows the mean naming latencies as a function of SOA and relatedness between prime and target.

Analysis of variance (ANOVAs) with the variables SOA and semantic relatedness revealed a main effect of SOA, $F_{1}(2,147)=5.51, M S E=4795 ; p<.01 ; F_{2}(2,98)=23.58, M S E=1124$, $p<.01$, a main effect of semantic relatedness, $F_{1}(1,147)=70.41, M S E=213, p<.01 ; F_{2}(1,49)$ $=17.48, M S E=865, p<.01$, and a significant interaction between SOA and semantic relatedness over participants, $F_{1}(2,147)=5.38, M S E=213, p<.01$, but not over stimuli, $F_{2}(2,98)=$ $1.91, M S E=406, p>.15$. Separate analyses of the different $S O A$ conditions revealed a significant priming effect in the 200-ms condition, $F_{1}(1,49)=34.50, M S E=284, p<.01 ; F_{2}(1,49)=$ $8.23, M S E=1105, p<.01$, the $84+14-m s$ condition, $F_{1}(1,49)=39.67, M S E=160, p<.01$; $F_{2}(1,49)=18.28, M S E=324, p<.01$, and the $57+14$-ms condition, $F_{1}(1,49)=5.70, M S E=$ $194, p<.05 ; F_{2}(1,49)=6.55, M S E=248, p<.05$. 
TABLE 1

Number naming latencies as a function of SOA and associative relationship between prime and target (Experiment 1)

\begin{tabular}{|c|c|c|c|}
\hline & \multicolumn{3}{|c|}{$S O A^{a}$} \\
\hline & 200 & $84+14$ & $57+14$ \\
\hline Related & 611 & 625 & 597 \\
\hline Unrelated & 632 & 641 & 604 \\
\hline Priming effect & 21 & 16 & 7 \\
\hline
\end{tabular}

\section{Discussion}

Experiment 1 replicated Delazer and Girelli (1997) with healthy participants and with tachistoscopically presented primes. The experiment showed a reliable 7 -ms associative priming effect at a prime exposure duration of $57+14 \mathrm{~ms}$ and very robust priming effects of more than 15 -ms at $84+14-\mathrm{ms}$ and 200 -ms exposure duration. This provides strong evidence that the multidigit numbers shown in the Appendix have representations in the brain that can be activated automatically by the words with which they are semantically related and with which they frequently co-occur. This strongly suggests that for familiar Arabic numerals there is a link between the visual input and some stored knowledge, so that these numbers need not be decomposed by the quantitative number-processing system in order to be named (remember that the primes had no relationship with the magnitudes represented by the numbers).

\section{EXPERIMENT 2}

One possible interpretation of the priming effect in Experiment 1 could be that it originates from associative relations in the phonological output lexicon. This would agree with Seron and Noël's (1995) suggestion that frequently used expressions are preassembled at the level of the verbal output lexicon. The prime would then trigger a preassembled representation and in this way speed up the naming of the number. Although such an interpretation is interesting, it would imply that the results of Experiment 1 need not have implications for the issue of nonsemantic routes in number processing, because in this scenario the priming is due to converging activation in the output lexicon and is caused by verbal stimuli (the primes), which are known to have nonsemantic letter-sound conversions. To find out whether this explanation is a likely candidate, we repeated the previous experiment with a number decision task that did not require the pronunciation of the numbers.

Participants were asked to indicate whether the stimulus that was presented constituted a true Arabic numeral or not. Non-numerals were made by replacing one digit by a capital letter (e.g., 1F92, Q2). We only ran the $84+14$-ms masked priming condition, as the effect in this condition was nearly as strong as that in the unmasked 200-ms condition (see Table 1) while 
the shorter presentation duration and the masking allowed us to be more certain that the priming was automatic.

\section{Method}

\section{Participants}

A new group of 50 students from the University of Huelva participated in the experiment.

\section{Stimuli}

The stimuli consisted of the 50 Arabic number trials from Experiment 1 (see Appendix) filled up with 50 non-number trials. The latter were created in such a way that the prime in no way informed the participant about the kind of target that would follow. This was done by taking prime words that in texts were also followed by numbers (e.g., other brand names and famous dates) and by having half of these primes followed by "related" non-numbers (i.e., non-numbers derived from the related number; an example in England could be "emergency -99B") and half followed by an "unrelated" non-number (e.g., "Battle of Hastings - 12F9").

\section{Procedure}

Each trial started with the presentation of hash marks (\#) for $500 \mathrm{~ms}$, immediately followed by the prime word(s) for $84 \mathrm{~ms}$, a postmask of hash marks for $14 \mathrm{~ms}$, and the target. Participants were asked to indicate as fast as possible whether the presented stimulus formed a legitimate Arabic numeral or formed a combined code of letters and digits. Response timing started at the onset of the target numeral. Nothing was said about the prime. Half of the targets were preceded by a related prime and half by an unrelated prime according to a Latin-square design. The 100 experimental trials were preceded by 15 practice trials.

\section{Results}

Error rate was low (2.4\%) and correlated positively with RT over the four cells of the design. Therefore, the analyses are limited to the RTs of the correct responses. Average RTs to number targets preceded by related and unrelated primes were respectively $586 \mathrm{~ms}$ and 611 ms. This priming effect of $25 \mathrm{~ms}$ was reliable over both participants and stimuli, $F_{1}(1,49)=$ $24.75, M S E=432, p<.01 ; F_{2}(1,49)=13.24, M S E=1025, p<.01$. Average RT to the nonnumber targets was $635 \mathrm{~ms}$.

\section{Discussion}

Experiment 2 was run to find out whether we could obtain an associative priming effect in a number-processing task that did not involve overt pronunciation of the Arabic numerals. This was indeed the case: Participants were $25 \mathrm{~ms}$ faster to decide that a target formed a legal Arabic numeral if the numeral was preceded by a related word than if it was preceded by an unrelated word. This makes it unlikely that the priming effect of Experiment 1 was entirely due to associative priming in the phonological output system. 


\section{GENERAL DISCUSSION}

In two experiments, we have shown that familiar complex Arabic numerals are not always processed by decomposing them into their constituent quantities, as suggested in some models of numerical cognition (e.g., Brysbaert, 1995; McCloskey, 1992). Our results clearly show that healthy people can recognise Arabic numerals in a non-quantitative way. They also indicate that the associative priming is unlikely to be due to the organization of the verbal output system, as suggested by Seron and Noël (1995).

Probably the simplest model to capture our data is one that contains two routes that are activated in parallel upon presentation of an Arabic numeral: one quantity-based pathway and one non-magnitude-related pathway. The processing speed of the routes determines how much they will contribute to the output. The quantity-based route can be used for all Arabic numerals, and its speed depends on factors such as number magnitude and priming with numbers that have a close value to the target (Brysbaert, 1995; Reynvoet \& Brysbaert, 1999; Reynvoet, Brysbaert, \& Fias, 2002). As indicated in the Introduction, for large numbers this route is also likely to involve a recoding of the number into a combination of smaller quantities (Brysbaert, 1995; Dehaene, 1992; McCloskey, 1992). The non-quantity-related route can only be used for Arabic numerals that we have encountered a number of times before, and its speed depends, at least in part, on priming with stimuli that often co-occur with the target in real life. Other factors such as frequency of occurrence of the numbers themselves might also play a role, but this is a topic that has yet to be fully explored.

Unfortunately, our data do not provide us with many more constraints about how to implement this non-magnitude-related route of Arabic numeral processing. Basically, there seem to be two options. First, we can follow the example of Cohen et al. (1994; see also Cuetos \& Miera, 1998) and postulate the existence of a visual input lexicon for Arabic numerals. The associative priming effect can be explained by assuming links between the Arabic input lexicon and stored encyclopaedic knowledge in the semantic system, or by postulating links between the orthographic input lexicon and the Arabic input lexicon for word-number combinations that frequently co-occur. In such a model, familiar multidigit numbers may have the same status as that of familiar word sequences such as compound words (e.g., teaspoon, honeymoon) or idioms (e.g., spill the beans, button your lips) within the orthographic input lexicon (see Cacciari \& Tabossi, 1988; Gibbs, 1994; Jackendoff, 1995; Sandra, 1990; and Zwitserlood, 1994, for research on these types of verbal stimuli). As remarked by Cohen et al. (1994), such a model might also allow for direct connections between the Arabic input lexicon and the phonological output lexicon, making it possible for people to read aloud familiar Arabic numerals without activating their meaning.

The alternative option is to conceive of the nonquantitative route for Arabic numeral processing as comprising direct connections between the visual Arabic number form (either the raw stimulus or a feature list representing more abstract digit forms) and stored encyclopaedic knowledge. According to this view, familiar Arabic numerals would be recognized more like pictorial images than like words (Fias, 2001; Fias et al., 2001). Argument for this view is that the associative priming is not restricted to words and Arabic numerals, requiring the existence of a lexicon for these two types of stimulus. Associative priming with verbal primes on nonverbal target stimuli is not restricted to the effects we reported in our 
experiments, but has been observed with other types of pictorial target as well, including pictures of objects (Alario, Segui, \& Ferrand, 2000) and faces (Carson \& Burton, 2001).

In summary, our experiments replicate previous neuropsychological findings in a population of normal participants (university undergraduates) and show that not all Arabic numeral processing is quantity based, as claimed in various models of numerical cognition. Further research will have to decide whether the extra non-quantity-related route is mediated by an Arabic input lexicon or not. One of the most convincing findings for the existence of an Arabic input lexicon would be a report of a neuropsychological patient who can name Arabic numerals without having any idea of their meaning, just like there is clinical evidence of patients who can name irregular words without understanding them (see Gerhand, 2001, for the most recent evidence on this issue). Most researchers agree that pictorial visual stimuli cannot be named without semantic mediation, precisely because there is no independent picture lexicon directly feeding into the phonological output lexicon (e.g., Hodges \& Greene, 1998). However, as Cohen et al. (1994), Delazer and Girelli (1997), and our studies have shown that the meaning of an Arabic numeral need not be based on the magnitude of the numeral; it can be any learned associates of the numeral.

\section{REFERENCES}

Alario, F. X., Segui, J., \& Ferrand, L. (2000). Semantic and associative priming in picture naming. Quarterly fournal of Experimental Psychology, 53A, 741-764.

Brannon, E. M., \& Terrace, H. S. (1998). Ordering of the numerosities 1 to 9 by monkeys. Science, 282 (5389), 746749.

Brysbaert, M. (1995). Arabic number reading: on the nature of the numerical scale and the origin of phonological recoding. Fournal of Experimental Psychology: General, 124, 434-452.

Brysbaert, M., Fias, W., \& Reynvoet, B. (2000). The issue of semantic mediation in word and number naming. In F. Columbus (Ed.), Advances in psychological research (Vol. I, pp. 181-200). Huntington, NY: Nova Science Publishers.

Cacciari, C., \& Tabossi, P. (1988). The comprehension of idioms. Fournal of Memory and Language, 27, 668-683.

Carson, D. R., \& Burton, A. M. (2001). Semantic priming of person recognition: Categorial priming may be a weaker form of the associative priming effect. Quarterly Journal of Experimental Psychology, 54A, 1155-1179.

Cipolotti, L., \& Butterworth, B. (1995). Toward a multiroute model of number processing: Impaired number transcoding with preserved calculation skills. Fournal of Experimental Psychology: General, 124, 375-390.

Cohen, L., Dehaene, S., \& Verstichel, P. (1994). Number words and number non-words: A case of deep dyslexia extending to Arabic numerals. Brain, 117, 267-279.

Cuetos, F., \& Alameda, J. R. (1997) El efecto frecuencia en el procesamiento de numeros. Un recuento de frecuencias. Cognitiva, 9, 207-223

Cuetos, F., \& Miera, G. (1998). Number processing dissociations: Evidence from a case of dyscalculia. The Spanish Journal of Psychology, 1, 18-31.

Dehaene, S. (1992). Varieties of numerical abilities. Cognition, 44, 1-42.

Dehaene, S., \& Cohen, L. (1997). Cerebral pathways for calculation: Double dissociation between route verbal and quantitative knowledge of arithmetic. Cortex, 33, 219-250

Dehaene S., Dehaene-Lambertz G., \& Cohen L. (1998). Abstract representations of numbers in the animal and human brain. Trends in Neurosciences, 21, 355-361.

Dehaene, S., Dupoux, E., \& Mehler, J. (1990). Is numerical comparison digital? Analogical and symbolic effects in two-digit number comparison. Fournal of Experimental Psychology: Human Perception and Performance, 16, 626641 .

Delazer, M., \& Girelli, L. (1997). When “Alfa Romeo” facilitates 164: Semantic effects in verbal number production. Neurocase, 3, 461-475. 
Fias, W. (2001). Two routes for the processing of verbal numbers: Evidence from the SNARC effect. Psychological Research, 65, 250-259.

Fias, W., Reynvoet, B., \& Brysbaert, M. (2001). Are Arabic numerals processed as pictures in Stroop interference task? Psychological Research, 65, 242-249.

Forster, K. I. (1998). The pros and cons of masked priming. Fournal of Psycholinguistic Research, 27, 203-233.

Gerhand, S. (2001). Routes to reading: A report of a non-semantic reader with equivalent performance on regular and exception words. Neuropsychologia, 39, 1473-1484.

Gibbs, R. W., Jr. (1994). Figurative thought and figurative language. In M. A. Gernsbacher (Ed.), Handbook of psycholinguistics (pp. 411-446). San Diego, CA: Academic Press.

Glaser, W. R. (1992). Picture naming. Cognition, 42, 61-105.

Hodges, J. R., \& Greene, J. D. W. (1998). Knowing about people and naming them: Can Alzheimer's disease patients do one without the other? Quarterly Fournal of Experimental Psychology, 51A, 121-134.

Jackendoff, R. (1995). The boundaries of the lexicon. In M. Everaert, E. J. Van der Linden, \& R. Schreuder (Eds.), Idioms: Structural and psychological perspectives (pp. 133-165). Hillsdale, NJ: Lawrence Erlbaum Associates, Inc.

Lucas, M. (2000). Semantic priming without association: A meta-analytic review. Psychonomic Bulletin $\mathbb{E}$ Reviem, 7, $618-630$.

McCloskey, M. (1992). Cognitive mechanisms in numerical processing: Evidence from acquired dyscalculia. Cognition, 44, 107-157.

Neely, J. H. (1991). Semantic priming in visual word recognition: A selective review of current findings and theories. In D. Besner \& G. W. Hymphreys (Eds.), Basic processes in reading: Visual mord recognition (pp. 264-336). Hillsdale, NJ: Lawrence Erlbaum Associates, Inc.

Noël, M. P., \& Seron, X. (1993). Arabic number reading deficit: A single-case study or when 236 is read (2306) and judged superior to 1258. Cognitive Neuropsychology, 10, 317-339.

Perea, M., \& Gotor, A. (1997). Associative and semantic priming effects occur at very short stimulus-onset asynchronies in lexical decision and naming. Cognition, 62, 223-240.

Poltrock, S. E., \& Schwartz, D. R. (1984). Comparative judgments of multidigit numbers. Fournal of Experimental Psychology: Learning, Memory, and Cognition, 10, 32-45.

Power, R. J. D., \& Dal Martello, M. F. (1997). From 834 to eighty thirty-four: The reading of Arabic numerals by seven-year-old children. Mathematical Cognition, 3, 63-85.

Reynvoet, B., \& Brysbaert, M. (1999). Single-digit and two-digit Arabic numerals address the same semantic number line. Cognition, 72, 191-201.

Reynvoet, B., Brysbaert, M., \& Fias, W. (2002). Semantic priming in number naming. Quarterly fournal of Experimental Psychology, 55A, 1127-1139.

Sandra, D. (1990). On the representation and processing of compound words-Automatic access to constituent morphemes does not occur. Quarterly Fournal of Experimental Psychology, 42A, 529-567.

Seron, X., \& Noël, M. P. (1995). Transcoding from the Arabic code to the verbal one and vice-versa: How many routes? Mathematical Cognition, 1, 215-243.

Thioux, M., Seron, X., \& Pesenti, M. (1999). Functional neuroanatomy of the semantic system: The case for numerals. Brain and Language, 69, 488-490.

Wynn, K. (1992). Addition and subtraction by human infants. Nature, 358 (6389), 749-750.

Zwitserlood, P. (1994). The role of semantic transparency in the processing and representation of Dutch compounds. Language and Cognitive Processes, 9, 341-368. 
APPENDIX

Stimuli used in Experiments 1 and 2

Fifty Arabic numerals and their word associates

\begin{tabular}{|c|c|c|c|}
\hline Prime & Target & Prime & Target \\
\hline SEAT & 600 & SEAT & 850 \\
\hline peugeot & 106 & peugeot & 205 \\
\hline alfa romeo & 145 & alfa romeo & 156 \\
\hline mercedes & 300 & mercedes & 190 \\
\hline SIMCA & 1000 & SIMCA & 1200 \\
\hline levi's & 501 & levi's & 519 \\
\hline brandy & 103 & coñac & 501 \\
\hline licor & 43 & odisea & 2001 \\
\hline retevision & 1050 & formula & 44 \\
\hline policia & 091 & turron & 1880 \\
\hline dálmatas & 101 & america & 1492 \\
\hline boeing & 747 & telefonica & 1004 \\
\hline porche & 911 & boeing & 437 \\
\hline guerra civil & 1939 & urgencias & 061 \\
\hline efecto & 2000 & guerra mundial & 1945 \\
\hline satan & 666 & apolo & 12 \\
\hline mayo & 68 & la pepa & 1812 \\
\hline revolucion rusa & 1917 & revolucion francesa & 1789 \\
\hline voltios & 125 & $\mathrm{a}$ & 49 \\
\hline invasión arabe & 712 & voltios & 220 \\
\hline chanel & 19 & chanel & 5 \\
\hline radio & 80 & antena & 3 \\
\hline tele & 5 & onda & 0 \\
\hline martes & 13 & eme & 30 \\
\hline expo & 92 & Barcelona & 92 \\
\hline
\end{tabular}

